\title{
Imaging of electrode position in relation to electrode functioning after cochlear implantation
}

\author{
Gijs K. A. van Wermeskerken • Adriaan F. van Olphen • \\ Kees Graamans
}

Received: 28 October 2008 / Accepted: 19 February 2009 / Published online: 24 March 2009

(C) The Author(s) 2009. This article is published with open access at Springerlink.com

\begin{abstract}
This study assessed the electrode position in cochlear implant patients and evaluated the extent to which the electrode position is determinative in the electrophysiological functioning of the cochlear implant system. Five consecutively implanted adult patients received a multichannel cochlear implant. In all patients, the electrical impedance and the electrically evoked compound action potentials were recorded immediately after implantation. Multislice computer tomography was performed 6 weeks postoperatively before switch-on of the cochlear implant. The electrode position relative to the modiolus was assessed and correlated to the electrophysiological measurements. All electrodes were fully inserted; this was confirmed by computer tomography. The individual electrode distance toward the modiolus could be most precisely analyzed for the basal part of the electrode array. It was thus decided to study the data of electrodes one, four, and seven. No correlation was found between electrical impedance and electrode distance. A significant correlation was found
\end{abstract}

G. K. A. van Wermeskerken ( $\square)$ · A. F. van Olphen · K. Graamans Department of Otorhinolaryngology,

Amphia Hospital, P.O. Box 90157,

4800 RL Breda, The Netherlands

e-mail: gijs@vanwermeskerken.com

Present Address:

A. F. van Olphen

Department of Otorhinolaryngology, Head and Neck Surgery,

University Medical Center Utrecht, P.O. Box 85500,

3508 GA Utrecht, The Netherlands

Present Address:

K. Graamans

Department of Otorhinolaryngology, Head and Neck Surgery, Radboud University Nijmegen Medical Center, P.O. Box 9101, 6500 HB Nijmegen, The Netherlands between electrode distance and the electrically evoked compound action potentials, with a $96 \%$ probability using Kendall's rank correlation. We conclude that the electrodemodiolus distance is of importance to the stimulation of auditory nerve fibers. Future developments in imaging will further improve and refine our insight in the relation between electrode positioning.

Keywords Cochlear implant · Evoked potentials . Neural response telemetry · Electric impedance · Computer tomography

\section{Introduction}

In cochlear implant patients, a large proportion of the success or failure depends on the transfer of stimulating signals from the electrode toward the auditory nerve fibers. An important aspect of the electrode design is electrical impedance, which depends on electrode surface area, morphological processes, and electrochemical processes initiated by electrical stimulation. The development of a new generation of cochlear implant devices as well as modern surgical techniques has, to a great extent, been aimed at improving stimulus-transferring mechanisms. In line with this trend, in the past years, the development of electrode arrays has been focused on the 'modiolus-hugging' type of electrodes. The advantages of these so-called perimodiolar designs include lower stimulation levels, a larger dynamic range, better channel separation, and improvement of speech understanding [1-3]. Despite the advantages of perimodiolar designs, concern about post-implant meningitis has prompted studies reassessing the electrode position after implantation [4]. Thus, there are multiple incentives to strive for an exact documentation of the position of the 
individual electrode in relation to cochlear structures and the insertion depth of the electrode array [5].

The aim of this study is first to meticulously assess the electrode position in cochlear implant recipients. Formerly, the plain X-ray Stenvers projection was used, but for obvious reasons this method has been abandoned $[6,7]$. The study considers the benefits of high-resolution CT (HRCT) scanning as a more exact method to visualize the structures of the temporal bone. The advantages of HRCT include the elimination of respiratory misregistration, decrease of other motion artifacts, and an obvious improvement in patient comfort by reducing the examination time [8]. The main disadvantage of HRCT in the postoperative assessment of a cochlear implant is image degradation, due to partial voluming and the metallic artifacts that may interfere with the visibility of individual electrodes $[7,9,10]$. We recently demonstrated the feasibility of imaging the electrode position within the intracochlear spaces on both an implanted temporal bone and a fresh human cadaver head [11]. So we assume that locating the electrode will be possible with HRCT and that this visualization will allow us to measure the distance to important landmarks in the cochlea, such as the modiolus. Therefore, this study was expected to achieve a standardized HRCT-based assessment of the distance between the electrode and the modiolus.

The second aim of this study is to investigate the possible relations between this morphological parameter and electrophysiological characteristics, that is the electrical impedance (EI) and the electrically evoked compound action potential (ECAP), as measured with neural response telemetry (NRT). The NRT system has become an easy-touse tool for measuring the ECAP generated by the auditory nerve following electrical stimulation of the cochlea via an electrode of the cochlear implant [12]. The data it yields are currently applied in various methods of fitting speech processors [13-16]. When NRT data are collected directly after implantation, we are much better informed about the ability to stimulate spiral ganglion cells. This information might help us to verify the position and function of the implanted electrodes.

The main question that is addressed in this study is to what extent the electrode position is determinative in the electrophysiological functioning of the cochlear implant system.

\section{Materials and methods}

\section{Subjects}

Five adult patients were included in this study. All of them were subsequently implanted with a Nucleus Contour cochlear implant (Cochlear Corp., Lane Cove, Australia)
Table 1 Patients' characteristics

\begin{tabular}{ll}
\hline Male/Female & $2 / 3$ \\
Mean age at implantation (range) & $58.8(45-75)$ \\
Mean age of deafness (range) & $28.3(4-45)$ \\
\hline
\end{tabular}

between October 2005 and November 2005 at the University Medical Center Utrecht. In all patients, the electrodes were inserted as planned, that is according to the insertion depth that had been set out. There were no surgical problems or complications. The patient characteristics are shown in Table 1. The causes of deafness in these patients were meningitis, a congenital and hereditary etiology, and trauma. In one patient, no etiology could be identified.

\section{Electrode impedance measurement}

The device was activated using the Windows-based Diagnostic and Programming System software (Win-DPS, release version 126) provided by the manufacturer (Cochlear Corp., Lane Cove, Australia). The stimuli consisted of biphasic current pulses presented at a level of 100 clinical current units, which is approximately $76 \mu \mathrm{A}$, and an impulse duration of $25 \mu \mathrm{s} / \mathrm{phase}$. In the present study, the EI was measured in common ground (CG) mode intra-operatively. In this mode, the impedance is measured between an intracochlear electrode and all other intracochlear electrodes coupled in parallel. Shortcut or open-circuit electrodes were not considered for data analysis. According to the specifications of the manufacturer, this implied the exclusion of data with impedances below 0.7 and above $20 \mathrm{kOhm}$, respectively.

\section{ECAP measurement}

The registration procedure of the ECAP responses was identical to the one we used in previous experiments [17]. The initial examination took place intra-operatively immediately after implantation. The ECAP responses were recorded using a computer equipped with NRT software, version 3.0, distributed by the Cochlear Corporation. We used a modified version of the protocol described by Abbas et al. [18]. Our test parameters are presented in Table 2. The stimulation mode was monopolar (MP1 mode), using

Table 2 ECAP test parameters

\begin{tabular}{ll}
\hline Stimulation rate & $80 \mathrm{~Hz}$ \\
Pulse width & $25 \mu \mathrm{s}$ \\
Masker level & $+5 \mathrm{CL}$ above probe level \\
Masker probe interval & $500 \mu \mathrm{s}$ \\
Gain/number of sweeps & $60 \mathrm{~dB} / 100$ or $40 \mathrm{~dB} / 200$ \\
Delay & $100 \mu \mathrm{s}$ \\
\hline
\end{tabular}


the extra cochlear ball reference electrode. Masker advance, which is the masker-probe interval, was fixed at $500 \mu \mathrm{s}$. As a rule, the sampling delay, i.e., the interval between stimulation and initiation of sampling, was set at $100 \mu \mathrm{s}$. In the event of amplifier saturation, the delay was adjusted until a satisfactory response was obtained. The amplifier gain was set at $60 \mathrm{~dB}$ but was decreased to $40 \mathrm{~dB}$ in cases of amplifier saturation. We set the number of sweeps at 100, whereas Abbas set it at 50. In conformance with the Abbas protocol, we set the pulse duration at $25 \mu$ s per phase. The stimulation levels are described in terms of current level (CL), a quantity defined by the Cochlear Company. The CL ranges from 1 to 255 current units (CU), which corresponds to electrical currents from $10 \mu \mathrm{A}$ to $1.75 \mathrm{~mA}$. Our aim was to test 22 electrodes (electrodes 122) intra-operatively. The electrodes selected for recording were two positions above the stimulation electrode. Thus, for each patient, we selected the second electrode, $\mathrm{N}+2$, from the stimulation electrode, $\mathrm{N}$, in the apical direction. An exception was made for electrodes 21 and 22, for which the recording electrodes were 19 and 20, respectively.

\section{Imaging}

Multislice CT was performed 6 weeks after implantation but before the first fitting of the speech processor, using the Philips Brilliance 64-slice CT (Philips Medical Systems, Cleveland, $\mathrm{OH}, \mathrm{USA})$. The patients were scanned with the following parameters, according to the imaging protocol we used in previous experiments [11]: $140 \mathrm{kV}$; effective tube current - time product of $260 \mathrm{~mA} / \mathrm{s}$; rotation time $0.5 \mathrm{~s}$. In order to maximize spatial resolution, the collimation was reduced to $2 \times 0.5 \mathrm{~mm}$. To reduce aliasing artifacts a low pitch factor of 0.35 was used. The corresponding measures of local exposure dose (CT dose indices, CTDI) was $136 \mathrm{mGy}$. An ultrahigh resolution mode was used for image acquisition. A corresponding ultrahigh resolution filter was applied for image reconstruction. In order to further optimize resolution, a field of view of $51 \mathrm{~mm}$ was chosen, resulting in a pixel size of $0.1 \mathrm{~mm}$. Datasets were transferred to a workstation (Easyvision; Philips, Best, The Netherlands) where 3-D reconstructions were created using multiplanar reformation (MPR), i.e., calculating slices along arbitrary sections. In our study, an MPR was made parallel to the basal turn of the cochlea and perpendicular to the modiolus and thus in the plane of the electrode array. Window width and window level were adjusted until both the cochlear tissues and the individual electrodes could be visualized.

\section{Statistical analysis}

All analyses were carried out with Wessa statistical software [19]. The Kendall tau rank correlation was used

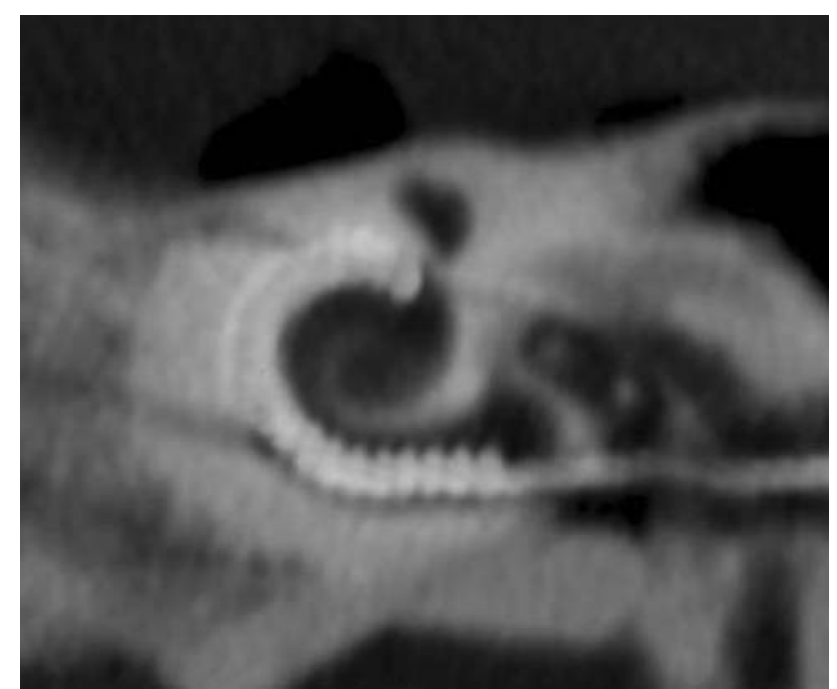

Fig. 1 HRCT image with an MPR in the plane of the electrode array

analyzing the correlation between the ECAP, electrode impedance versus electrode distance.

\section{Results}

In all five patients the electrode arrays were fully inserted, and this was confirmed by HRCT (Fig. 1). After initial data analysis the distance of the apical electrodes to the modiolus could not be visualized. The distance of the more basally located electrodes could be reliably assessed, however. In general, about half of all the electrodes inserted could be identified separately (range 8-14). With the limitation of not being able to analyze the more apical part of the array, it was decided to restrict our investigation to the data of electrodes one, four, and seven, as these electrodes could be clearly distinguished in all five patients. Moreover, possible differences between electrophysiological parameters presumably are more apparent with a larger inter-electrode distance.

The distance from the three examined electrodes toward the modiolus is illustrated in Fig. 2. Note that in all five patients a decrease in electrode distance is clearly visible.

Second, we investigated the relationship between the electrode position, the EI, and the ECAP. No shortcut or open-circuit electrodes were measured. In patient 3 , no ECAP recordings could be obtained on the study electrodes since the surgical procedure had to be shortened for anesthesiological reasons. No correlation was found between the EI and electrode position. A correlation was found between the electrode distance and the ECAP with a 96\% probability using Kendall's rank correlation. In Fig. 3 the electrode-modiolus distance is plotted against the ECAP levels. 


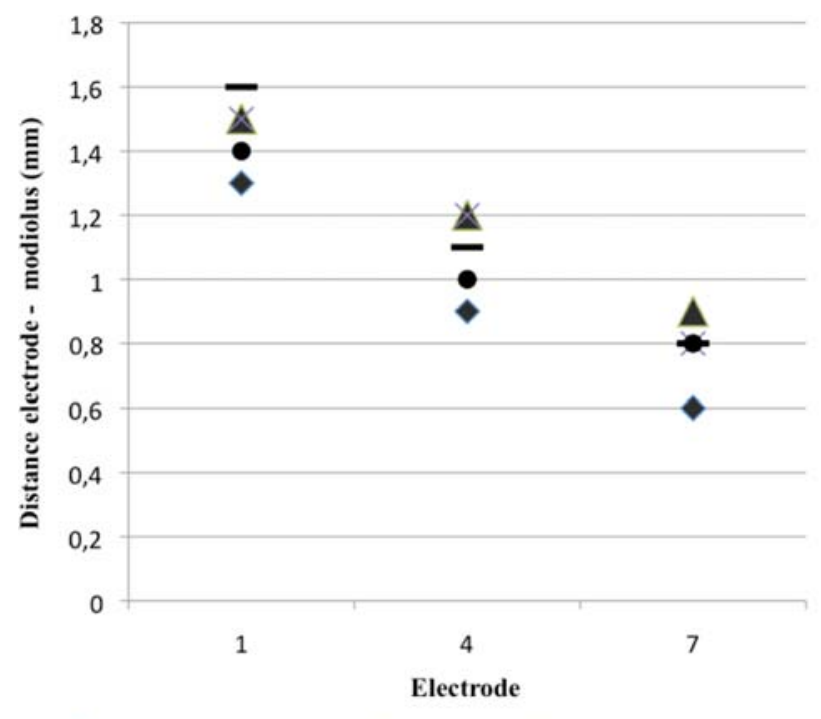

$\bullet$ patient 1 - patient $2 \Delta$ patient $3 \times$ patient $4 \bullet$ patient 5

Fig. 2 Distance electrode-modiolus

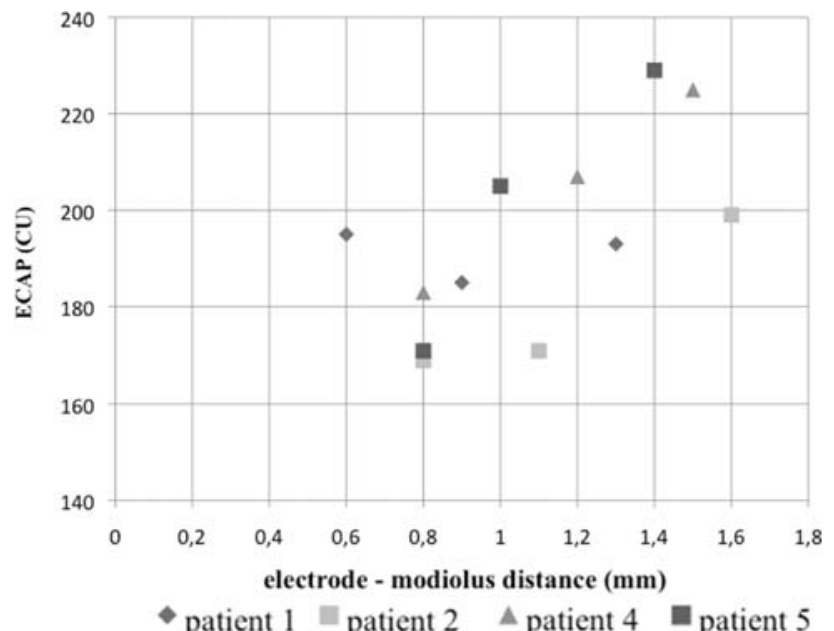

Fig. 3 Electrode-modiolus distance versus ECAP

\section{Discussion}

In this study, we examined the value of HRCT in assessing the electrode position of cochlear implant recipients. Using an MPR in the plane of the electrode array enabled us to count the number of implanted electrodes in all patients. HRCT seems to have a clear advantage over the previously used plain film radiography with the standard Stenvers projection. With modern multislice CT scanning, more detailed information can be gathered on the intracochlear electrode position. Thus it may be helpful in the assessment of intracochlear damage after implantation, such as degradation of the modiolar wall [20]. When determining the exact position of the electrode in the cochlea, it was difficult to identify the separate electrodes in relation to the modiolus. This was mainly due to image degradation caused by partial volume effects, but metallic artifacts of the electrode array also posed a problem [7, 9, 10]. The window depth in our software configuration limited us in visualizing the three extreme contrasts we wanted to investigate: the fluid compartment of the cochlea; the bony structures of the cochlea and modiolus; and the radiopaque electrode array. In the future, technical improvements in both soft- and hardware will further improve the spatial resolution in HRCT under such extreme contrast conditions.

The second part of this study addressed the relation between electrode distance and electrophysiological parameters. First of all we evaluated the possible relationship between the EI and the electrode-modiolus distance. We could not demonstrate such a relationship. We presume that this is due to the small number of electrodes that we measured. In an earlier study, however, we analyzed the electrical impedance in 52 Nucleus Contour electrode arrays. This showed us a small decrease in electrical impedance in the apical direction. This decrease was especially notable in the first five electrodes [21]. One explanation of this observation is that the more basally located electrodes are less 'modiolus-hugging' than the apical ones. The higher electrical impedance can be explained by the larger fluid compartment, which leads to more growth of less conductive fibrous tissue.

A significant correlation was found between the electrode-modiolus distance and the ECAP. Our data suggest that a higher electrode-modiolus distance leads to a higher ECAP. Again the small number of electrodes that could be investigated was a limitation in our analysis. Electrode stimulation led to selective triggering of auditory nerve groups. In this process, many factors are important; the electrode-modiolus distance is just one part of this complex process.

In conclusion, the results of this study suggest that electrode-modiolus distance is of importance in the stimulation of the auditory nerve fibers. In the development of new cochlear implant systems, optimizing the electrode positioning in relation to the modiolus may influence the functional outcome. Further development in HRCT will help us to analyze the electrode positioning postoperatively. This should further increase and refine our insight in the importance of electrode positioning in relation to aspects of electrophysiological functioning. This may eventually lead to an improvement in the functioning of cochlear implant systems in hearing impaired persons.

Conflict of interest statement The authors declare that they have no conflict of interest. 
Open Access This article is distributed under the terms of the Creative Commons Attribution Noncommercial License which permits any noncommercial use, distribution, and reproduction in any medium, provided the original author(s) and source are credited.

\section{References}

1. Blamey PJ, Pyman BC, Gordon M, Clark GM, Brown AM, Dowell RC et al (1992) Factors predicting postoperative sentence scores in postlinguistically deaf adult cochlear implant patients. Ann Otol Rhinol Laryngol 101(4):342-348

2. Finley CF (1990) Models of neural responsiveness to electrical stimulation. In: Miller JMSF et al (eds) Cochlear implants: models of the electrically stimulated ear. Springer, New York, pp 55-93

3. Shepherd RK, Hatsushika S, Clark GM (1993) Electrical stimulation of the auditory nerve: the effect of electrode position on neural excitation. Hear Res 66(1):108-120. doi:10.1016/0378-5955 (93) $90265-3$

4. Reefhuis J, Honein MA, Whitney CG, Chamany S, Mann EA, Biernath KR et al (2003) Risk of bacterial meningitis in children with cochlear implants. N Engl J Med 349(5):435-445. doi:10.1056/ NEJMoa031101

5. Verbist BM, Frijns JH, Geleijns J, van Buchem MA (2005) Multisection CT as a valuable tool in the postoperative assessment of cochlear implant patients. AJNR Am J Neuroradiol 26(2):424-429

6. Bettman RH, Van Olphen AF, Zonneveld FW, Huizing EH (2003) Electrode insertion depth in cochlear implantees estimated during surgery, on plain film radiographs and with electrode function testing. Eur Arch Otorhinolaryngol 260(10):536-540. doi:10.1007/ s00405-003-0593-z

7. Xu J, Xu SA, Cohen LT, Clark GM (2000) Cochlear view: postoperative radiography for cochlear implantation. Am J Otol 21(1):49-56

8. Valvassori GA (2005) Imaging of the temporal bone. In: Mafee MF, Valvassori GE, Becker M (eds) Imaging of the head and neck, 2nd edn. Georg Thieme Verlag, Stuttgart, p 30

9. Ketten DR, Skinner MW, Wang G, Vannier MW, Gates GA, Neely JG (1998) In vivo measures of cochlear length and insertion depth of nucleus cochlear implant electrode arrays. Ann Otol Rhinol Laryngol Suppl 175:1-16

10. Whiting BR, Bae KT, Skinner MW (2001) Cochlear implants: three-dimensional localization by means of coregistration of CT and conventional radiographs. Radiology 221(2):543-549. doi:10.1148/radiol.2212010275
11. van Wermeskerken GK, Prokop M, Van Olphen AF, Albers FW (2007) Intracochlear assessment of electrode position after cochlear implant surgery by means of multislice computer tomography. Eur Arch Otorhinolaryngol 264(12):1405-1407. doi:10.1007/ s00405-007-0389-7

12. Lai WK, Dillier N, Laszig R, Fisch U (1997) Results from a pilot study using the nucleus CI24 M/SP5 cochlear implant system. Am J Otol 18(6 Suppl):S35-S36

13. Brown CJ, Hughes ML, Luk B, Abbas PJ, Wolaver A, Gervais J (2000) The relationship between EAP and EABR thresholds and levels used to program the nucleus 24 speech processor: data from adults. Ear Hear 21(2):151-163. doi:10.1097/00003446-20000 4000-00009 see comments

14. Seyle K, Brown CJ (2002) Speech perception using maps based on neural response telemetry measures. Ear Hear 23(1 Suppl):72S79S. doi:10.1097/00003446-200202001-00009

15. Smoorenburg GF, Willeboer C, van Dijk JE (2002) Speech perception in nucleus CI24 M cochlear implant users with processor settings based on electrically evoked compound action potential thresholds. Audiol Neurootol 7(6):335-347. doi:10.1159/ 000066154

16. Thai-Van H, Chanal JM, Coudert C, Veuillet E, Truy E, Collet L (2001) Relationship between NRT measurements and behavioral levels in children with the Nucleus 24 cochlear implant may change over time: preliminary report. Int J Pediatr Otorhinolaryngol 58(2):153-162. doi:10.1016/S0165-5876(01)00426-8

17. Van Wermeskerken GK, Van Olphen AF, van Zanten GA (2006) A comparison of intra- versus post-operatively acquired electrically evoked compound action potentials. Int $\mathrm{J}$ Audiol 45(10):589-594. doi:10.1080/14992020600833189

18. Abbas PJ, Brown CJ, Shallop JK, Firszt JB, Hughes ML, Hong SH et al (1999) Summary of results using the nucleus CI24 M implant to record the electrically evoked compound action potential. Ear Hear 20(1):45-59. doi:10.1097/00003446-199902000-00005

19. Wessa P (2008) Free statistics software, office for research development and education. http://www.wessa.net [computer program]. Version 1.1.22-r6

20. Richter B, Jaekel K, Aschendorff A, Marangos N, Laszig R (2001) Cochlear structures after implantation of a perimodiolar electrode array. Laryngoscope 111(5):837-843. doi:10.1097/00005537200105000-00015

21. van Wermeskerken GK, van Olphen AF, Smoorenburg GF (2006) Intra- and postoperative electrode impedance of the straight and Contour arrays of the Nucleus 24 cochlear implant: relation to T and $\mathrm{C}$ levels. Int $\mathrm{J}$ Audiol 45(9):537-544. doi:10.1080/ 14992020600825466 